\title{
Tribo-corrosion Behavior of Electroless Ni-P Coatings in Alkaline Corrosive Environment
}

\author{
Bikash Panja and Prasanta Sahoo* \\ Department of Mechanical Engineering, Jadavpur University, Kolkata 700 032, India
}

Received 15 September 2014; accepted 28 October 2014

\begin{abstract}
The present article considers an experimental study of tribo-corrosion behavior of electroless $\mathrm{Ni}-\mathrm{P}$ coatings in alkaline environment sliding against alumina. The study of wear and friction behaviour is carried out using different load and sliding speed with the help of a pin-on-disk tribometer. The wear rate increases with decrease in sliding speed and increase in the applied load. The friction coefficient initially decreases with increase in the applied load and then remains at nearly steady level at higher applied load. Also, it is found that the friction coefficient is lower at higher sliding speed. The friction coefficient does not change with the sliding duration after the initial transient running-in time. The coating is characterized using scanning electron microscopy (SEM), energy dispersive X-ray (EDX) analysis and X-ray diffraction (XRD) analysis. The wear mechanism is also studied and has been found to be mostly abrasive in nature.
\end{abstract}

Keywords: Electroless Ni-P coating, Tribo-corrosion, Friction, Wear, Alkaline environment.

\section{Introduction}

Electroless coating method is widely used to protect the base material from damage. Electroless plating deposition was proposed by Brenner and Riddell in the middle of the last century [1,2]. Electroless nickel coatings are used in different applications such as aerospace, aviation, automotives, oil and gas processing, food processing, microelectronics, radio electronics, computer engineering, chemical processing, textiles, machinery, mining and metallization of plastic etc. $[3,4]$. Electroless Ni-P (EN) coatings have found extensive use in surface engineering due to their excellent mechanical, physical, electrical, corrosion and tribological properties [5-7]. The properties and microstructures of

\footnotetext{
* Corresponding author. E-mail address: psjume@gmail.com, psahoo@mech.jdvu.ac.in
} 
EN coatings depend on the amount of phosphorous alloyed in the deposit $[7,8]$. EN coating provides natural lubricity due to the presence of phosphorous content and it is further improved by annealing $[9,10]$. The mechanical and tribological properties of these coatings can further be improved by the incorporation of hard particles [11], heat treatment [8, 12] and dry lubricants [13, 14]. Heating the coating at $400{ }^{\circ} \mathrm{C}$ for $1 \mathrm{~h}$, results in highest hardness $[15,16]$. Electroless Ni-P coating is also found to have good anti-corrosive properties due to the presence of phosphorus [17, 18]. Anti-corrosive properties of EN coating increase with increasing phosphorus content [19].

Mechanical components fabricated out of commonly available materials are usually not compatible with corrosive environment. Moreover, many modern types of machineries are subjected to extreme corrosive environments viz. marine applications, chemical industry, petrochemical industry, etc. Due to the dynamics involved, these machineries would require protection against both wear and corrosion simultaneously as they undergo tribo-chemical interactions. EN coatings are widely used as corrosion resistance material in caustic environment, especially in petrochemical industries [20]. These coatings have also been applied to the surface of glass fiber reinforced plastic (GFRP) substrate for making blades of offshore wind turbine installations [21]. The aim of the present work is to study the friction and wear behaviour of electroless Ni-P coating in alkaline corrosive environment. The coating characterization is done with the help of scanning electron microscopy, energy dispersive X-ray and X-ray diffraction analysis.

\section{Experimental details \\ Preparation of coatings}

Mild steel (AISI 1040) cylindrical substrates of size $\varnothing 4 \mathrm{~mm}$ and $30 \mathrm{~mm}$ long are used for the deposition of electroless Ni-P coating. Turning, parting and grinding processes are used for the preparation of the solid cylindrical substrates. The substrate samples before coating are subjected to roughness evaluations (center line average values, $\mathrm{Ra}$ ) and the substrates which showed as little as about $0.1 \%$ variation in roughness are selected for deposition. The roughness measurements are carried out using a surface profilometer (Taylor Hobson, Surtronic 3+). The substrates are mechanically cleaned of dust and foreign particles with the help of soap and water. Acetone is then employed to clean any remaining organic products. Before coating the substrates are subjected to pickling treatment in dilute $(18 \%)$ hydrochloric acid for one minute to ensure the removal of surface layer formed like rust or other oxides. Subsequently, the samples are rinsed in distilled water followed by methanol cleaning prior to coating. The bath composition and operating conditions for electroless Ni-P coating are selected after several experimentations, and proper ranges of parameters for stable deposition are chosen accordingly (enlisted in Table 1). 
Table 1. Ingredients of electroless bath and their ranges.

\begin{tabular}{|l|l|c|}
\hline Sl. No. & \multicolumn{1}{|c|}{ Parameters } & Range of parameters \\
\hline 1 & Nickel sulphate & $25 \mathrm{~g} / \mathrm{L}$ \\
\hline 2 & Nickel chloride & $25 \mathrm{~g} / \mathrm{L}$ \\
\hline 3 & Sodium hypophosphite & $24 \mathrm{~g} / \mathrm{L}$ \\
\hline 4 & Sodium succinate & $12 \mathrm{~g} / \mathrm{L}$ \\
\hline 5 & Deposition temperature & $80^{\circ} \mathrm{C}$ \\
\hline 6 & pH of solution & 4.5 \\
\hline
\end{tabular}

EN deposition is carried out using nickel sulphate and nickel chloride (source of nickel), sodium hypophosphite (reducing agent) and sodium succinate (stabilizer). The $\mathrm{pH}$ value of the bath is maintained at a fixed value by adding required quantity of dilute hydrochloric acid. The cleaned samples are activated in palladium chloride at $55^{\circ} \mathrm{C}$ temperature. This step is necessary to kick start the deposition on the substrate as soon as it is placed inside the electroless bath. The coating is carried out for a period of 4 hours (after 2 hours of deposition, the substrate is taken out and rinsed with distilled water and then again placed in a freshly prepared bath of same composition for another 2 hours. This is done to get requisite coating thickness which is necessary for carrying out the tribological tests on the coating). The coating thickness is found to lie around 50 microns as evident from the micrograph of the cross section of the coating (Fig. 1). Deposition time is kept constant for each and every specimen so that the average coating thickness remains approximately the same. The surface roughness of electroless Ni-P coating is found to be in the range $0.62-0.83 \mu \mathrm{m}$. After the deposition is over, samples are washed with distilled water. The coated samples are annealed in a box furnace for 1 hour at $400{ }^{\circ} \mathrm{C}$.

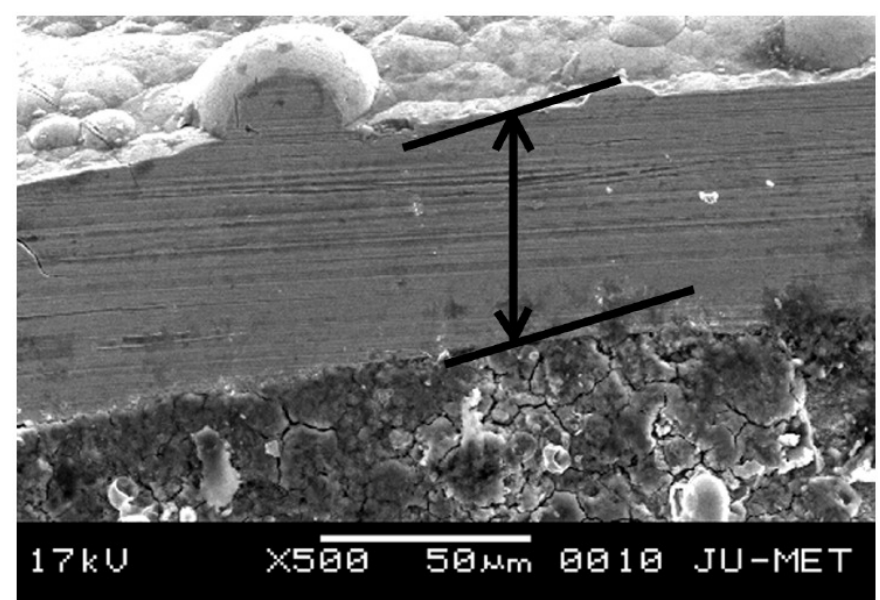

Figure 1. Micrograph for cross section of Ni-P coating.

\section{Tribo-corrosion test in alkaline environment}

Tribo-corrosion tests (wear and friction tests) of EN coated specimens are conducted in a Wear \& Friction Monitor (TR-208-M2, Ducom, India) using a 
pin-on-disk configuration. The tests are carried out in alkaline medium $(10 \%$ $\mathrm{NaOH}$ solution) at ambient temperature $\left(28{ }^{\circ} \mathrm{C}\right)$. A pictorial view of the experimental set-up is shown in Fig. 2. The coated specimens serve as test specimens which are held perpendicular against a rotating alumina disk $(\varnothing 100$ $\mathrm{mm} \times 8 \mathrm{~mm}$ thickness). As the hardness of the counter disk (alumina) is 1680 $\mathrm{HV}_{1}$, which is higher than the hardness of Ni-P coated specimen (average microhardness value is $880 \mathrm{HV}_{1}$ ), the counter disk material undergoes negligible wear compared to the coated specimen. Normal load is applied by placing dead weights on loading pan. The depth of wear is measured by a LVDT (Syscon) which has a measurement range of $\pm 2 \mathrm{~mm}$ with accuracy of $0.1 \pm 1 \% \mu \mathrm{m}$. The frictional force is measured by a frictional force sensor (IPA) that uses a beam type load cell (range 0 to $100 \mathrm{~N}$ ) with accuracy of $0.1 \pm 2 \% \mathrm{~N}$. The experiments are carried out at sliding speed ranging from $0.084-0.126 \mathrm{~m} / \mathrm{s}$ and load in the range of $10-50 \mathrm{~N}$ for 10 min duration considering the small coating thickness. Wear rate is evaluated by the following expression: wear rate $=$ mass loss / (density $\times$ sliding distance). The mass loss due to sliding test is evaluated by weighing the pins before and after each test on a digital balance with accuracy up to $0.01 \mathrm{mg}$. The density of the EN coating is considered as $8.0 \mathrm{~g} / \mathrm{cc}$.

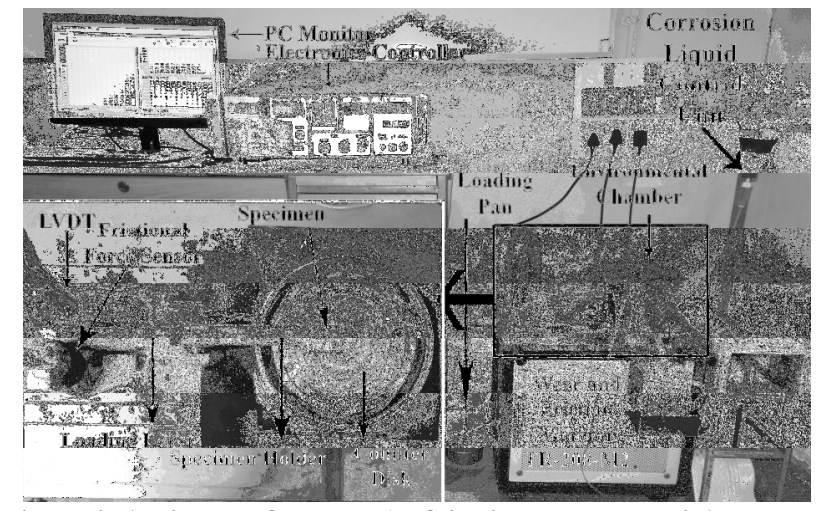

Figure 2. Pictorial view of wear \& friction setup with top view (inset).

\section{Coating characterization}

The coating is characterised by its surface morphology, composition and phase structure. In the present study, surface morphology of the coating is observed by SEM (JEOL, JSM-6360) to analyze the microstructure of the deposited coatings before and after heat treatment at $400{ }^{\circ} \mathrm{C}$. SEM is also done after tribological testing to see the wear track patterns in order to predict the wear mechanism. EDX analysis (Inca, Oxford) is done in conjunction with SEM to study the composition of the EN coatings in terms of the weight percentages of nickel and phosphorous. The crystalline phase structure is studied with the help of X-ray diffraction (XRD) analysis (Rigaku, Ultima III) so that the different precipitated phases both pre and post heat treatment can be identified.

\section{Results and discussion}

\section{Wear behavior}

Wear rate of the electroless Ni-P coating in alkaline medium as function of the applied load under different sliding speeds is shown in Fig. 3. It is observed that 
the wear rate increases with decreasing the sliding speed and gradually increases with the increase in the applied load up to $40 \mathrm{~N}$ beyond which the wear rate decreases with increasing in the applied load.

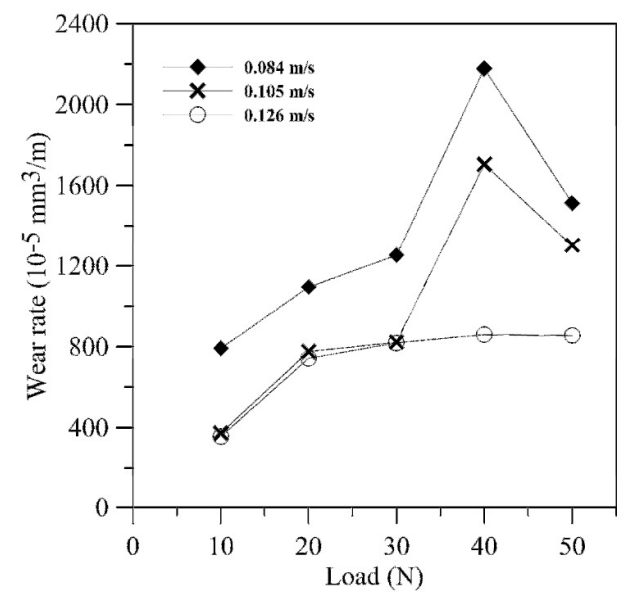

Figure 3. Wear rate as function of the applied load in alkaline medium.

Wear rate of electroless Ni-P coating as function of the applied load $(10 \mathrm{~N}-50 \mathrm{~N})$ is shown in Fig. 4 for both alkaline medium and dry condition with constant sliding speed $(0.105 \mathrm{~m} / \mathrm{s})$ and test duration $(10 \mathrm{~min})$. The wear rate of EN coating gradually increases with increase in load for both alkaline medium and dry condition but the same decreases after $40 \mathrm{~N}$ load in alkaline medium. Also it is observed from the plot that wear rate is higher in $\mathrm{NaOH}$ solution compared to dry condition. This is because alkaline environment produces corrosive effects at the sliding interface. In the present study in alkaline medium, the wear rate increases gradually with increasing with applied load but it decreases after applied load of $40 \mathrm{~N}$ at all sliding velocities. However, for dry condition, the wear rate shows a continuous increasing trend. This may partly be explained by the fact that the corrosion resistance in the case of a metal or an alloy depends on the presence of reaction layers at its surface. These layers may sometimes be only a few atoms thick, resulting from an interaction between the material and the surrounding environment. Such layers can be formed as oxides, solid precipitates, adsorbed layers, or passive surface films. Some of them like dense oxide layers, precipitates, or passive films play a protective role by isolating the underlying metal from a direct contact with a surrounding corrosive environment. Now, continuous breakdown is believed to occur due to the mechanical rubbing. But at a load of $40 \mathrm{~N}$ the surface layer exposed to the alkaline environment may be repassivating to form a stronger layer which may be contributing to lower wear rate.

\section{Friction behavior}

Friction coefficient of EN coating in alkaline medium as function of the applied load for different sliding speeds is shown in Fig. 5. It is noticed that the friction coefficient decreases with increase in the applied load and then remained at nearly steady level at higher applied load. Also, it is found that the friction coefficient is in general lower at higher sliding speed. 


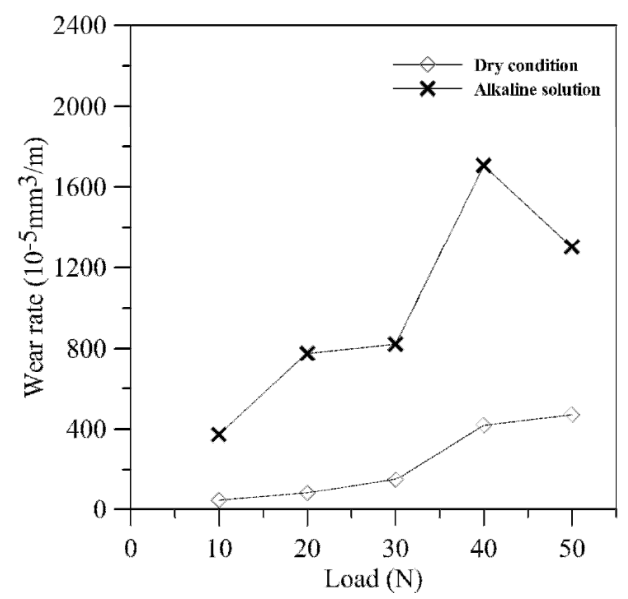

Figure 4. Wear rate as function of the applied load at constant sliding speed $(0.105 \mathrm{~m} / \mathrm{s})$ in alkaline medium and dry condition.

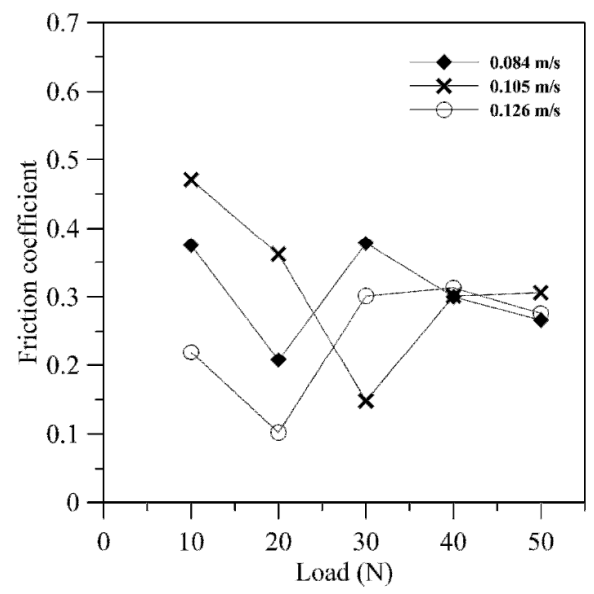

Figure 5. Friction coefficient as function of the applied load in alkaline medium at different sliding speeds.

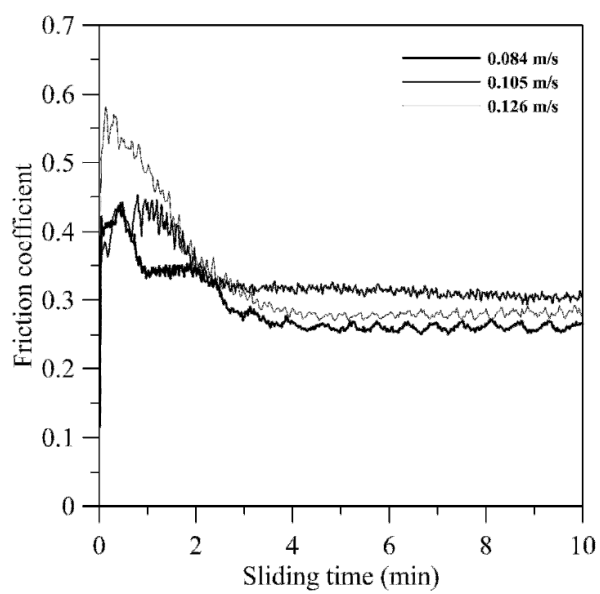

Figure 6. Friction coefficient against sliding time in alkaline medium at an applied load of $50 \mathrm{~N}$ and different sliding speeds.

Fig. 6 indicates the representative curves of friction coefficient of EN coating in alkaline medium at an applied load of $50 \mathrm{~N}$ for different sliding speeds. The friction coefficient does not change with the sliding duration after the initial transient running-in time. It is clear that after two minutes, no significant change 
in friction coefficient is detected. Also the steady-state value of the friction coefficient is nearly the same for different sliding speeds.

Fig. 7 shows the friction behavior of EN coating between $\mathrm{NaOH}$ solution and dry condition for constant sliding speed $(0.105 \mathrm{~m} / \mathrm{s})$ and varying load. The friction coefficient of EN coating decreases with increase in the load for both alkaline medium and dry condition but the friction coefficient in $\mathrm{NaOH}$ solution is lower than at the dry condition. This may be due to lubrication and cooling effect in alkaline environment.

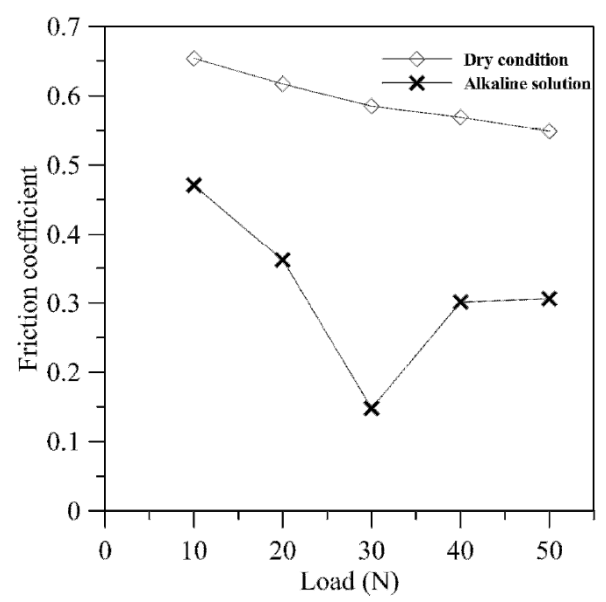

Figure 7. Friction coefficient against load in alkaline medium and dry condition.

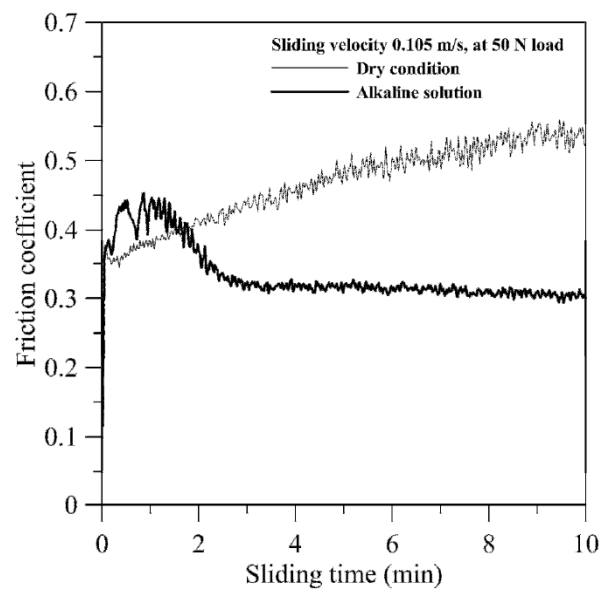

Figure 8. Friction coefficient against test duration in alkaline medium and dry condition.

Fig. 8 illustrates the representative curves of the friction coefficient of EN coating for sliding in $\mathrm{NaOH}$ solution and dry condition at an applied load of $50 \mathrm{~N}$ for constant sliding speed $(0.105 \mathrm{~m} / \mathrm{s})$. In $\mathrm{NaOH}$ solution, the friction coefficient does not change significantly with sliding duration after the initial transient running-in time. It is clear that after two minutes, no remarkable change of friction coefficient is detected in $\mathrm{NaOH}$ solution. But the friction coefficient in dry condition gradually increases with increase in test duration. Also, the friction coefficient in dry condition is higher than in $\mathrm{NaOH}$ solution. 


\section{Wear mechanism}

Wear of materials in corrosive solution is dominated by many different factors, depending on the materials, the geometry of the wear couple and the operating conditions. These wear mechanisms can be mainly classified into two groups, which are primarily dominated by the chemical and mechanical behaviors of the wear couple [22]. SEM micrograph of the worn surface after wear testing is shown in Fig. 9. It is clear from the figure that the load is taken by all of nodules. The presence of longitudinal grooves along the sliding direction with high degree of plasticity can be clearly observed. This is indicative of the occurrence of micro-cutting and micro-ploughing effect and characterized as ductile failure. Almost no pits or prows are observed on the worn surface. Hence it can be concluded that the abrasive wear is the predominant wear mechanism.

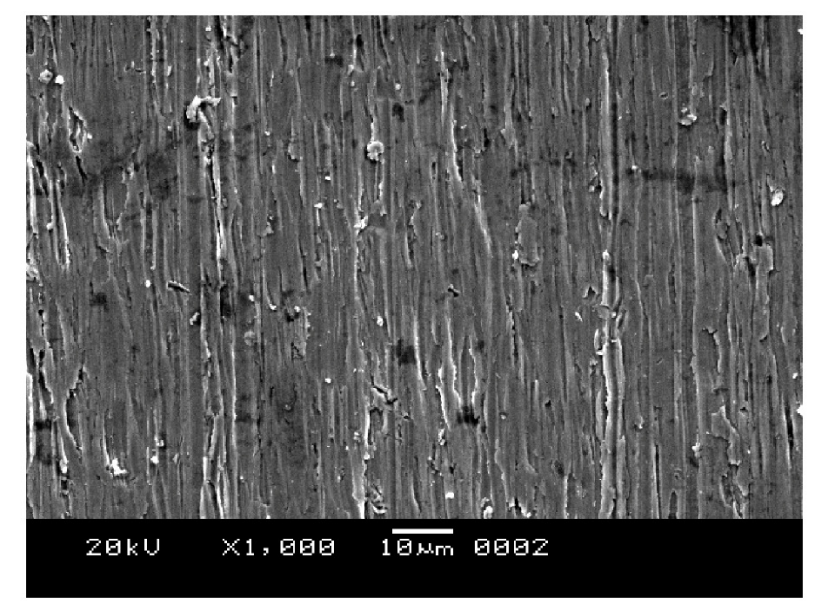

Figure 9. SEM micrograph of the worn surface.

\section{Coating surface morphology and compositional study}

Microstructure study

The SEM micrographs of coating surface in as-deposited and heat-treated (at 400

${ }^{\circ} \mathrm{C}$ for 1 hour) conditions are shown in Fig. 10. The micrographs of these surfaces exhibit many globular particles on the surface of the substrate. The surface is optically smooth and of low porosity. No obvious surface damage is found. The surface of the EN coatings appears to be dense. Also, by careful observation, it can be noted that the Ni-P nodules are quite deflated and flat in as-deposited condition but grow in size with heat treatment giving rise to coarse grained structure.

\section{Compositional study}

The percentages of nickel and phosphorous of the electroless $\mathrm{Ni}-\mathrm{P}$ deposits are determined using an EDX analyzer coupled to SEM. The EDX analysis of the coated samples is shown in Fig. 11. From EDX analysis, the average weight percentage of nickel and phosphorous is around $91.5 \%$ and $8.5 \%$, respectively. With heat treatment and change in other process parameters, no significant change in nickel and phosphorous content is observed. 


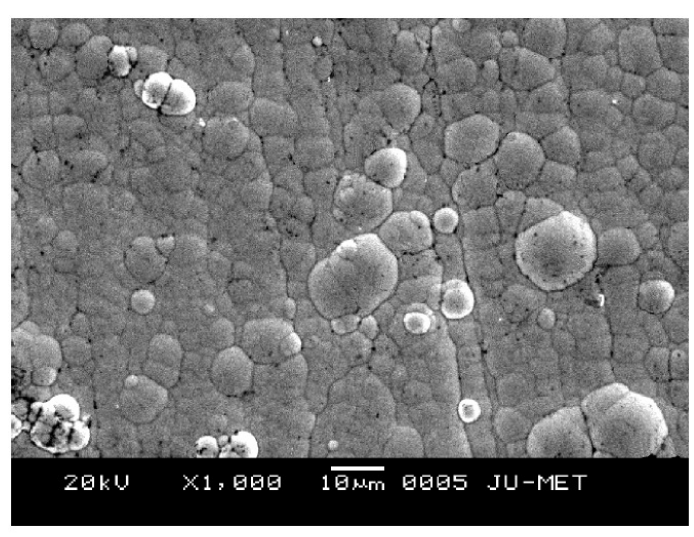

(a)

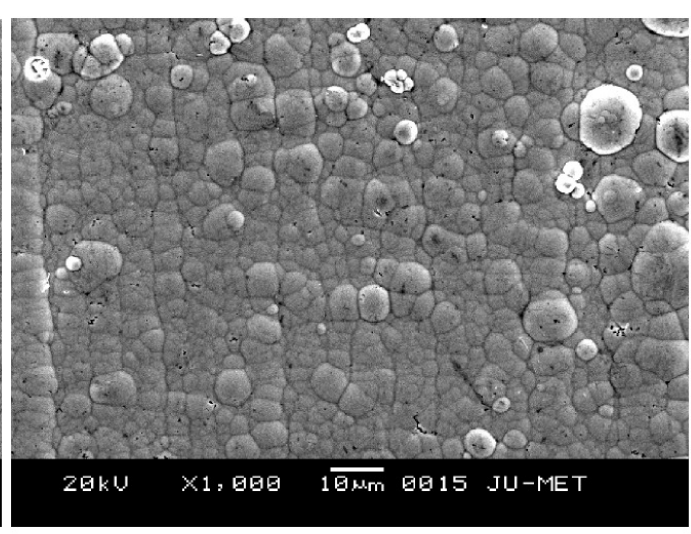

(b)

Figure 10. SEM micrographs of electroless Ni-P coatings: (a) as-deposited and (b) heattreated.

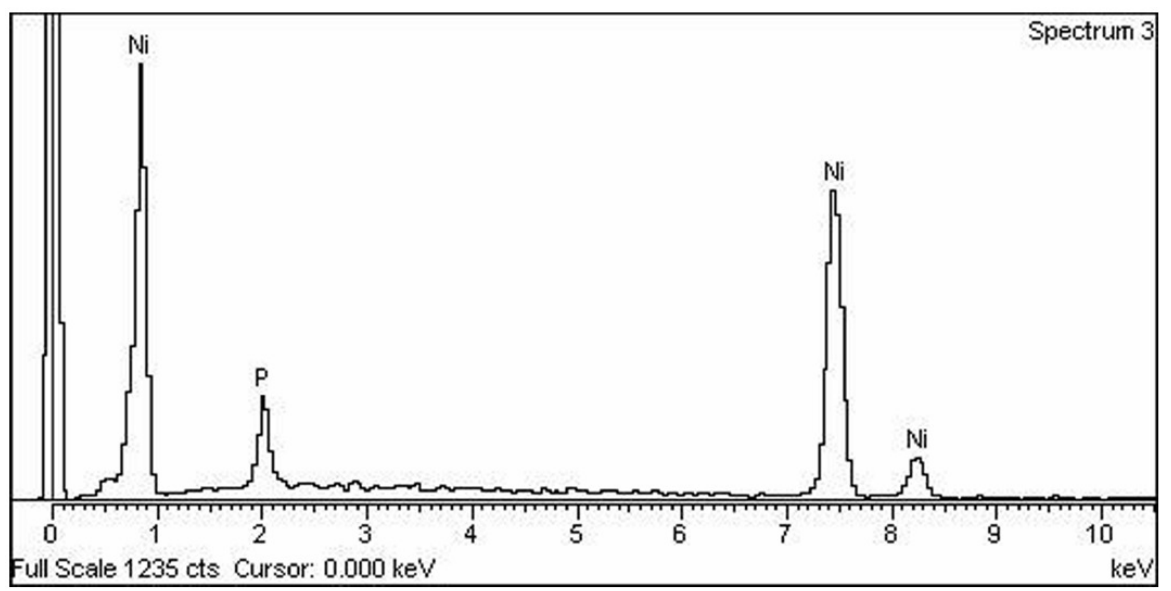

Figure 11. EDX plot of EN coatings.

\section{Phase structure study}

The major phases in the coatings both before and after heat treatment are indentified by XRD analysis with $\mathrm{Cu} \mathrm{K} \alpha$ radiation. Fig. 12 shows the XRD plots of as-deposited and annealed $\left(400{ }^{\circ} \mathrm{C}\right)$ coatings.

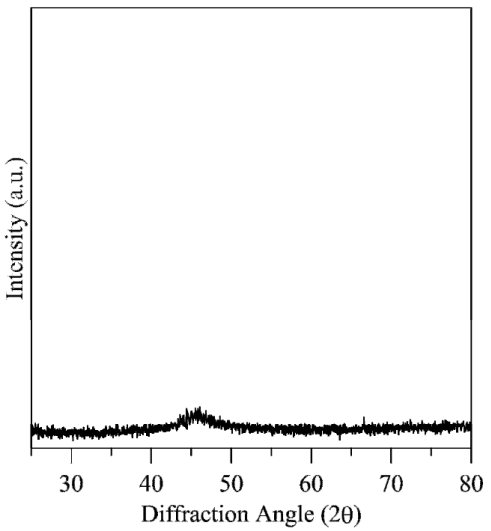

(a)

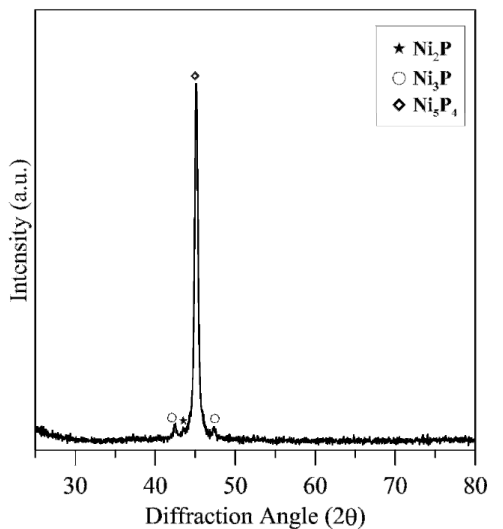

(b)

Figure 12. XRD plots of EN coating in (a) as-deposited and (b) heat-treated condition. 
From the figures, it is evident that in as-deposited condition the phase is mostly amorphous but turns crystalline with heat treatment. The major peaks of $\mathrm{Ni}_{2} \mathrm{P}$, $\mathrm{Ni}_{3} \mathrm{P}$ and $\mathrm{Ni}_{5} \mathrm{P}_{2}$ are found in heat-treated specimen. Hence, the $\mathrm{Ni}-\mathrm{P}$ coating changes with temperature to produce various nickel phosphide compounds (as observed in XRD plots) which may be impeding the movement of dislocations thereby contributing to the hardness of the coating.

\section{Conclusions}

Tribo-corrosion behavior of electroless Ni-P coatings in alkaline environment sliding against alumina is studied. The wear rate of Ni-P coating decreases slightly with sliding speed and increases with applied load up to $40 \mathrm{~N}$. The wear rate gradually increases with increase in load for dry condition but decreases after $40 \mathrm{~N}$ in alkaline medium. Wear rate is lower in dry condition compared to $\mathrm{NaOH}$ solution because the alkaline medium has corrosive effects. The friction coefficient of electroless Ni-P coating decreases with increase in load under alkaline medium at applied loads of $10 \mathrm{~N}-40 \mathrm{~N}$. The friction coefficient is also lower at higher sliding speeds. The friction coefficient decreases with increase in load for both $\mathrm{NaOH}$ solution and dry condition. However, friction coefficient in $\mathrm{NaOH}$ solution is lower than at dry condition because alkaline medium provides lubrication and cooling effect. Also, friction coefficient in dry condition gradually increases with increase in test duration. It is observed that the surface of the coatings is smooth, of low porosity and dense, with average nickel and phosphorous content of around $91.5 \%$ and $8.5 \%$, respectively. The coatings are amorphous in as-deposited condition but after heat treatment, the coating turns to crystalline with different nickel phosphide compounds deposits.

\section{Acknowledgement}

The authors gratefully acknowledge the support provided by UGC, Govt. of India through UPE-II program of Jadavpur University.

\section{References}

1. Brenner A, Riddell GE. J Research National Bureau Standards. 1946;37:31.

2. Brenner A, Riddell GE. Nickel plating by chemical reduction. US Patent US2532282; 1950.

3. Riedel W. Electroless nickel plating. Finishing Publication Ltd, UK; 1991.

4. Sahoo P. Surf Interface Analysis. 2008;40:1552.

5. Sahoo P, Das SK. Mater Design. 2011;32:1760.

6. $\quad$ Sudagar J, Lian J, Sha W. J Alloys Comp. 2013;571:183.

7. Agarwala RC, Agarwala V. Sadhana. 2003;28:475.

8. Hur KH, Jeong JH, Lee DN. J Mater Sci. 1990;25:2573.

9. Ramalho A, Miranda JC. Wear. 2005;259:828.

10. Novak M, Vojtech D, Vitu T. Appl Surf Sci. 2010;256:2956.

11. Huang YS, Zeng XT, Annergren I, et al. Surf Coat Technol. 2003;167:207. 
12. Apachitei I, Duszczyk J, Katgerman L, et al. Scripta Materialia. 1998;38:1347.

13. Straffelini G, Colombo D, Molinari A. Wear. 1999;236:179.

14. Zhao Q, Liu Y, Muller-Steinhagen H, et al. Surf Coat Technol. 2002;155:279.

15. Staia MH, Castillo EJ, Puchi ES, et al. Surf Coat Technol. 1996;86-87:598.

16. Wang L, Gao Y, Xu T, et al. Appl Surf Sci. 2006;252:7361.

17. Bai A, Chuang P, Hu C. Mater Chem Phys. 2003;82:93.

18. Nava D, Davalos CE, Martinez-Hernandez A, et al. Int J Electrochem Sci. 2013;8:2670.

19. Bigdeli F, Allahkaram SR. Mater Design. 2009;30:4450.

20. Hassani Sh, Raeissi K, Azzi M, et al. Corros Sci. 2009;51:2371.

21. Lee CK. Surf Coat Technol. 2008;202:4868.

22. Sarkar AD. Friction and Wear. Academic Press Inc., London; 1980. 